\title{
Fire, Flames and Dimensional Analysis
}

\author{
P. H. THOMAS \\ Kings Cottage \\ 1 Red Road \\ Borehamwood, Herts WD6 4SW, UK
}

\section{ABSTRACT}

In the context of the relationship between the fire safety engineer and the fire scientist a few scientific and engineering problems are discussed. Some comments are made about engineering theories of plumes and flames and a dimensionless correlation of the length of flames from a corner source under a ceiling is presented. Fire safety engineers may now be able to exploit a thermal theory of upward flame spread using data obtained by recently developed flammability tests.

KEYWORDS: flames, flame spread, ceilings, compartment fires

\section{INTRODUCTION}

In pursuing the objectives of understanding fire and its effects, and mitigating the consequent harm, we in this Association seek scientific and quantitative paths. We thereby seek to connect fire safety science with physics and chemistry and other basic sciences. Likewise fire safety engineers seek to connect their discipline with other branches of engineering. These things said in introduction, I wish to explore some of the by-ways of several well known topics involved in the study of compartment fires, particularly those on the boundary of fire safety science and fire safety engineering.

\section{PLUMES AND FLAMES}

There is much literature on plumes and flames $(1)\{2\}$ - at least on those which are vertical in an unbounded space and those plumes which become ceiling jets ${ }^{(3)}$. Some questions await resolution by computational fluid dynamics, some by the basic physics of turbulence but there are even some problems, unresolved at the engineering level. Before the 'invention' of the entrainment coefficient by Morton, Taylor \& Turner( 4 ), Taylor $(5)$ himself, following Schmidt(6) and Rouse, Yih and Humphreys $(7)$ had studied plumes and jets by exploiting the observation, that far from the source plumes and jets were straight sided in uniform atmospheres, and by recognizing the existence of similarity. 
Experimental data allowed a determination of the angle of expansion ' $\theta$ '; today they determine the entrainment coefficient ' $E$ '. For axi-symmetric plumes, however, a definition is required of an effective radius to which $\theta$ and $E$ are related.

The assumption of a Gaussian profile replaces the immediate need for a theory of turbulence but we still have to define ' $E$ ' in relation to the assumed distribution. Moreover it is different for axi-symmetric and line plumes.

Within these and other limitations velocity and temperature rise at a height ' $z$ ' above the source can be expressed as:

$$
W_{c}(z) \propto \sqrt{\mathrm{gz}} \text {. Funct }\left(Q^{*} \cdot \frac{\mathrm{z}}{\mathrm{D}}\right)
$$

and

$$
\theta_{c} / \mathrm{T}_{\circ} \propto \text { Funct }\left(Q^{*} \cdot \frac{z}{\mathrm{D}}\right)
$$

respectively:

where $D$ here is some specified linear size defining the source and $Q^{*}$ is a dimensionless fire power. In the far field defined by $z / D \gg 0$, results cannot depend on $D$ separately from the fire power $Q^{*}$ but for real fires where $D / z$ is significant we must expect some influence of the fire size. Moreover some of the conventional boundary layer assumptions (negligible pressure effects, negligible vertical diffusion) may no longer obtain near the source.

In the lower reaches of the flame there is a double peaked distribution of velocity and temperature across a horizontal section. Cetegen et $\mathrm{al}^{(8)}$ idealised this as in Fig 1 .

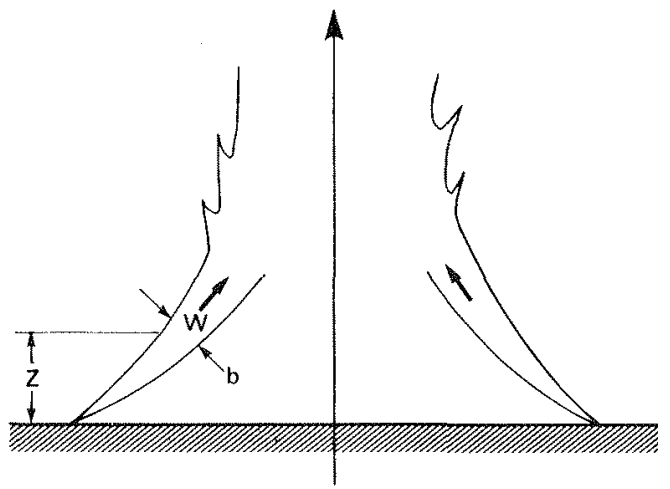

Figure 1 Lower flame zone, (after Cetegen et al (8)) 
They neglected the inclination and treated the flame as a zone of constant temperature (controlled by the molecular diffusion of air) and so obtained the velocity in the lower combustion zone as

$$
\text { W } \propto z^{1 / 2}
$$

continuity of mass gives:

$\frac{d}{d z}\left(\begin{array}{lllll}w & b & \rho\end{array}\right) \propto \frac{1}{b}$

Hence:

$$
\text { b } \propto z^{1 / 4}
$$

and the total entrainment, ie diffusion up to a height ' $z$ ' is

$$
m=C \cdot \eta \cdot P \cdot z^{3 / 4}
$$

where $C$ is a constant with respect to $z$ and $P$ is the flame perimeter. If $n$ is replaced by an eddy diffusivity proportional to:

$$
\text { w.b. } \alpha z^{3 / 4}
$$

one obtains a result given, assuming turbulent entrainment, by Thomas ${ }^{(9)}$.

$$
\text { viz m } \propto \mathrm{Pz}^{3 / 2}
$$

An oddity in contemporary fire engineering circles is that Hinkley $(10)$ has shown that this form works well for axi-symmetric plumes, ie that for $\mathrm{P}$ constant, $\mathrm{z}^{3 / 2}$ is a better representation of $\mathrm{dm} / \mathrm{dz}$ than $Q^{1 / 3}$ $\mathrm{z}^{5 / 3}$ as an expression of mass flow for $0.2<0 "<0.75 \mathrm{~kW} / \mathrm{m}^{2}$ and $\mathrm{P} \kappa \mathrm{z} / 2$.

$$
\text { Since } Q \propto q^{\prime \prime} P^{2}
$$

where $q^{\prime \prime}$ is a rate of heat release per unit area:

the ratio of $\mathrm{Pz}^{3 / 2}$ to $\left(\frac{Q}{E}\right)^{1 / 3} z^{5 / 3}$ is $\left(\frac{\mathrm{E} \cdot \mathrm{P}}{\mathrm{q}^{11}}\right)^{1 / 3} \frac{1}{z^{1 / 6}}$

Hinkley acknowledges the limitations to this apparent superiority. It is noteworthy that any slight tendency for $E$ to increase with height would go some way to "explaining" what appears to be a fortuitous result. 
Unfortunately there is a tendency to exploit this relationship, acknowledging its empiricism and convenience without attempting to resolve the problems and without recognising that even this "superiority" is peculiar to axi-symmetric plumes.

For strip and line plumes the Lee \& Emmons $(11)$ relation is widely used so the empirical preference for the $z^{3 / 2}$ relationship applies to a limited range of shapes and $Q^{*}$.

A peculiarity of these conventional engineering relations may be demonstrated by considering the line plume where the vertical central velocity is constant in the far field. A small restricting disturbance to the vertical flow - such as would be effected by a hypothetical insulated wire gauze - will not affect the new far field velocity but the local reduction in vertical velocity produces less entrainment and less dilution, so higher mean temperatures obtain.

Bearing in mind the assumption of similarity one might suspect that this curious conclusion is essentially the consequence of assuming a constancy of the horizontal distribution and of neglecting the role of local eddies. The same result is obtained for a point source axi-symmetric plume but it is easier to see the result $y i t h$ the line plume. The problem may be important when dealing with zone models in which a plume meets a density discontinuity.

Does this demonstrate that engineering plume theories are less robust than one perhaps thought they were?

There are some other problems. The values of $E$ for two and three dimensional plumes are different though this is a matter of little concern to the engineer. Secondly the transformation effected by Morton (12) which allows the far field strong plume equations to be transformed into those for the weak plume (albeit assuming a top hat profile) does not work for two-dimensional plumes. The modified plume radius:

$$
B=b \sqrt{\frac{\rho}{\rho_{0}}}
$$

is necessarily associated with the modification:

$$
E_{\rho}=E_{\rho_{\circ}} \sqrt{\frac{\rho}{\rho_{0}}}
$$

but to effect a simple change of the strong line plume equations into those of a weak plume one would require:

$$
B=b \frac{\rho}{\rho_{0}}
$$


which can only be realised easily with:

$$
E_{\rho}=E_{\rho o}
$$

Consider the Ricou - Spalding (13) relationship (on which equation (10) is based)

$$
\frac{d m}{d z}=C\left(\rho_{0} M\right)^{1 / 2}
$$

Because one must employ mass and momentum per unit length $\mathrm{m}^{\prime}$ and $\mathrm{M}^{\prime}$ respectively another dimension is required if ${ }^{\prime} \mathrm{C}$ ' is to remain dimensionless.

The variable $0^{*}$ which incorporates buoyancy (it includes $g$ ) has a physical meaning only above the top of the combustion zone. Below that it is a surrogate variable for mass or air flow. Clearly it has limited physical significance because of the combination of $g$ with a horizontal dimension.

The relationship:

$$
L \propto Q^{2 / 5}
$$

can perhaps be regarded as an algebraically manipulated expression of entrainment surface and velocity of entrainment:

$L^{2} \sqrt{g L} \propto 0$

More generally, if a flame shape factor $(=f(L / D))$ for a given fuel can be defined by

$$
\begin{aligned}
\mathrm{F} & =\frac{\text { fuel supply }}{\text { air entrainment }}=f(\mathrm{~L} / \mathrm{D}) \\
& =\frac{Q}{\mathrm{~L}^{2} \sqrt{\mathrm{gL}}}
\end{aligned}
$$

one obtains:

$$
\frac{L}{D}=\text { Funct }\left(Q^{*}\right)
$$


In the correlation used for flames by McCaffrey $(14)$ and others the characteristic length is:

$$
\frac{1}{g}\left(\frac{g^{2} Q}{p_{0} C_{p} T_{0}}\right)^{2 / 5}
$$

which is physically related to the distance to a given dilution. The ratio of this length to the size of the source $D$ is $0^{* 2 / 5}$. The earlier use by Thomas $(9)$ of:

$$
\frac{m_{f}}{\rho D^{2} \sqrt{g D}}
$$

emphasised, for a given fuel, the relative importance of momentum to buoyancy.

If the combustion zone is of length $H$ and energy is released uniformly over the height ' $\mathrm{H}$ ', the plume correlation must be in the form:

$$
\begin{aligned}
& \frac{\theta}{\mathrm{T}_{0}} \propto \text { Funct }\left(Q^{*}, \frac{\mathrm{z}}{\mathrm{D}}, \frac{\mathrm{H}}{\mathrm{D}}\right) \\
& \mathrm{W} \propto \sqrt{\mathrm{gz}} \text { Funct }\left(Q^{*}, \frac{z}{\mathrm{D}} \frac{\mathrm{H}}{\mathrm{D}}\right)
\end{aligned}
$$

but in a flame, $\mathrm{H}$ is a dependent variable, defined by a degree of dilution eg for a given fuel by $\theta$. Then $\theta / \mathrm{T}_{\circ}$ and $w$ are again functions only of $Q *$ and $z / D$ though not the same ones as for a plume.

\section{NON-VERTTCAL FLAMES}

\section{Flames out of Openings}

Plumes and Elames out of windows were first studied by Yokoi(15) and several later correlations have been presented.

There is a problem in defining the origin of external plumes and flames, since the exit flow is usually a horizontally moving layer, with buoyancy and momentum, often related. In an attempt to decouple this exit flow from the properties of the compartment Morgan and Marshall(16), in a 'zone' model of the emerging plume, have coupled a horizontal flux of buoyancy (potential energy) with a vertical flux of mean kinetic energy.

The use of the more accurate mean momentum flux would require estimating a volume determining the buoyancy of the turning flow (see Fig 2). 


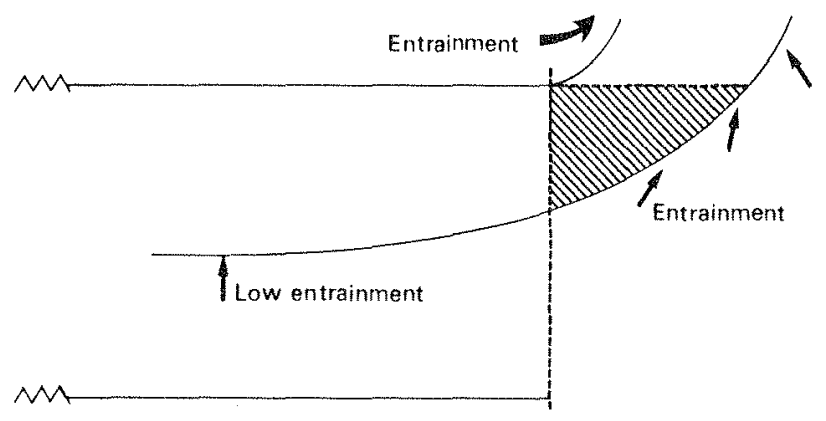

Figure 2 A turning flow

Taking the vertical flux distribution as Gaussian there has to be an 'ad hoc' matching owing to the problems introduced in the description of the turning.

Virtually all other attempts to deal with this problem have attached the empiricism to the definition of the position of a virtual source.

The connection between plumes and flames was exploited by Yokoi (15) who identified a mean flame length with the distance to an isotherm.

Flames under Ceilings

A connection between plumes and flames can be further utilised in correlating the lengths of flames ' $L$ ' extending horizontally $(17)$ from $a$ corner above a burner as in Fig 3 .

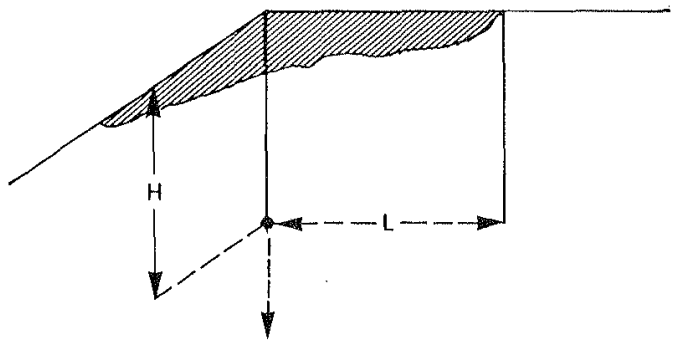

Figure 3 Flames from corner source below ceiling

For a 'point' source we provisionally might expect, on dimensional grounds, a correlation of the form:

$$
\frac{\mathrm{L}}{\mathrm{H}}=\text { Funct }\left[\frac{\mathrm{Q}}{\rho_{\mathrm{O}} \mathrm{C}_{\mathrm{p}} \mathrm{T}_{\mathrm{O}} \mathrm{H}^{2} \sqrt{\mathrm{gH}}}, \frac{\sqrt{\mathrm{gH}} \cdot \mathrm{H}}{\nu}\right]
$$

The first term in the brackets defines a $Q^{*}$ in terms of $H$. 
The second term must be included to accommodate the wall friction and the damping of turbulence under the ceiling.

The effect of a finite source of size ' $D$ ' introduces another variable $\mathrm{D} / \mathrm{H}$ but for small values of $\mathrm{D} / \mathrm{H}$ we shall assume here a simplification such as:

$$
\mathrm{H}^{*}=\mathrm{H}+\mathrm{C} \cdot \mathrm{D}
$$

where $C$ is a constant or a function of $Q^{x}$ as in Heskestad's correlation for vertical plumes(18).

Although in principle we cannot derive the value of $C$ from that of an axi-symmetric plume, we shall begin at the simplest choice, (a neutral plume) devised by Taylor (5) for axi-symmetric plumes viz $1.5 \sqrt{A_{F}}$, where $A_{F}$ is the fire area, which applied to a corner (and a square fire) gives (see Fig 4):

$$
\mathrm{H}^{*}=\mathrm{H}+3 \mathrm{D}
$$

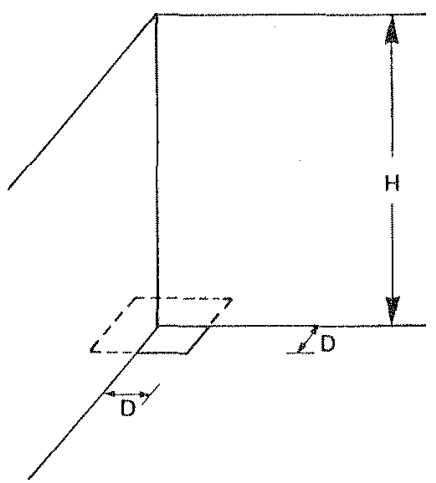

Figure 4 A corner source

Babrauskas $(19)$, using a more detailed argument derived $\mathrm{C} \sim 2.94$ in calculations interpreting the data of You and Faeth ${ }^{20}$. Their experiments were on a smalier scale than those of Gross ${ }^{(21)}$.

Babrauskas had interpreted flame length as being defined by a degree of air entrainment proportional to the fuel flow but attempted direct calculation. Here we seek only a dimensionless correlation.

Two sets of data(21,22), based on visual observations, give the correlation shown in Fig 5. Attempting to remove the dependence on $\mathrm{H}^{*}$ by plotting $L$ versus $Q^{2 / 5}$ is unsatisfactory.

The correlation:

$\frac{\mathrm{L}}{\mathrm{H}^{*}}+0.6=8 \sqrt{\mathrm{Q}^{*}}$ 


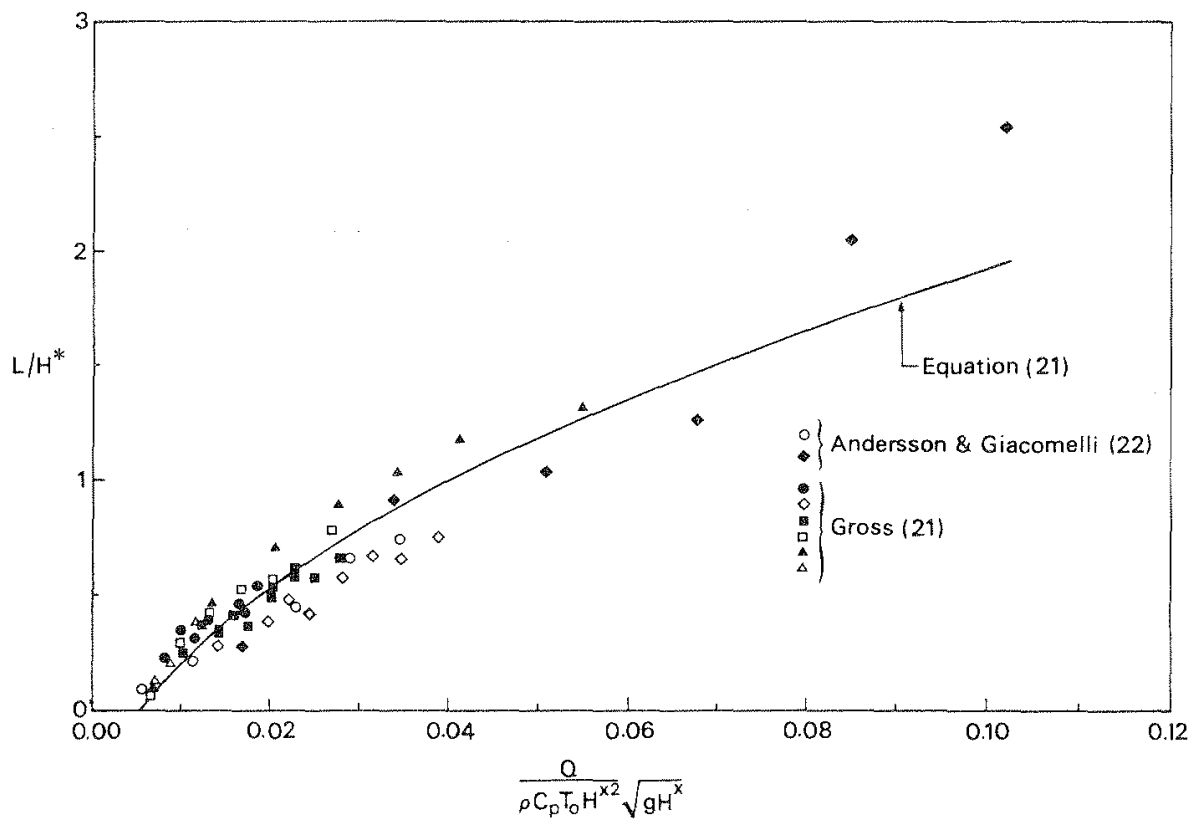

Figure 5 Correlation of tame lengths under ceilings in a cornet configuration

was chosen to correspond with that of Heskested and Delichatsios (23) for a ceiling plume in which we have substituted 40 for their $Q$ and $\mathrm{H}^{*}$ for $\mathrm{H}$. Matching was effected by choosing the isotherm for $180^{\circ} \mathrm{C}$.

The data of Andersson \& Giacomelli(22) also lie in this correlation but the values of $L$ for the You and Faeth data are relatively larger.

No residual effect of $\mathrm{H}^{*}$ was found, so friction on the walls or viscous forces elsewhere was not manifested in this correlation, though it may have some influence on the data of You and Faeth.

A corner is not a quadrant of the full axi-symmetric plume; flames extend near the corner of the wall and ceiling ${ }^{(24)}$ and so extend into what would be the low temperature region if a quadrant.

This type of relationship between plumes and flames is what Yokoi himself exploited.

It is an oddity (but an explicable one) that ' $g$ ' appears associated with a horizontal dimension for vertical flames and with a vertical dimension for flames under a horizontal surface. 
Although there has been much research in the last 25 years on fire growth the older problem of the fully developed compartment fire is still with us, if only in relation to harmonising design codes in Europe. The purposes of understanding such fires are to improve and cheapen design and to restrict spread, rather than to save lives directly. The compartment fire has not yet been the subject of much computational fluid dynamics so despite the sophistications by structural and heat transfer engineers the compartment fire is still, for design purposes, treated as at uniform temperature with wall surface emissivities sometimes chosen "post-hoc". Paradoxically, the compartment is usually treated as a "well stirred" reactor to provide uniform temperature with no internal flow (no accelerations in calculating the flow in and out of the openings).

The simplest heat balance assuming ventilation control with small terms (eg radiation loss) omitted is:

$\left(m_{a}+m_{f}\right) C_{p} \theta+h \cdot A_{q} \cdot \theta=\frac{m_{a}}{r} \Delta H$.

The air flow into the "well stirred reactor" is rather insensitive to temperatures above about $400^{\circ} \mathrm{C}$ and then for a compartment with a single opening,

$$
\mathrm{m}_{\mathrm{a}} \propto \mathrm{A}_{\mathrm{w}} \sqrt{\mathrm{H}_{\mathrm{w}}}
$$

where $A_{w}$ is the opening area and $H_{w}$ is its height and $h$ is the average heat transfer coefficient for the whole envelope area $A_{T}$ :

Hence if $\mathrm{ma}_{\mathrm{a}} \gg \mathrm{m}_{\mathrm{f}}$ :

$$
\left.\theta=\frac{\Delta H}{C_{p} \cdot\left[1+\frac{h \cdot A_{T}}{C_{p} A_{w} \sqrt{H_{w}}}\right.}\right]
$$

The term $\frac{A_{T}}{A_{W} \sqrt{\mathrm{H}_{W}}}$

appears extensively in the early literature often without reference to variations in ' $h$ ' with which it is associated in a dimensionless variable. A more pressing problem in recent years has been the effect of the fuel properties. The considerable empirical element in structural fire safety design is due to the major use of wood fuel and the prevalence of ventilation controlled fires. There are equations in the literature where both fuel properties and ventilation factors appear; the experiments they describe are not yet interpreted in terms of "state of the art" theory and present a challenge to fire safety engineers. 
The work described by Tewarson(25), Friedman $(26)$, Babrauskas \& Wickstrom (27), Bøhm and Hadvig(28), and Bullen and Thomas $(29)$ and others shows how decreasing the heat of pyrolysis or of evaporation produces extra fuel which extends the flame from the opening (and reduces the mean temperature inside the compartment). The assumption of stoichiometry removes the need to calculate the thermal coupling between the fire and the fuel in providing safe design for structures within the compartment but one needs to calculate the thermal coupling in order to assess the severity of the hazard and the propensity for fire spread outside the compartment.

The problem became important when structural engineers began designing buildings with their load bearing elements outside the building facade.

\section{FLAME SPREAD}

\section{Opposed Flow}

The spread of flame over flammable solids and the effects of pressure, oxygen etc have been extensively studied for opposed flows, though there was, for a time, a preponderance of data on PMMA.

With the theoretical understanding that has been achieved, some "simplification" can be developed for the benefit of the engineer who is mainly interested in the comparative performance of materials in various configurations as floors, ceilings, walls and corners. The principal theoretical simplifications which so far have been exploited are the result of the assumption of a large Damkohler number and the decoupling of the gas phase from the condensed phase so as to treat the heat transfer rate as an experimentally based quantity. This exploits the concept in de Ris's(30) theory for spread over thin materials; gas phase theory enables the value of the heat transfer to the whole of a strip of unit width ahead of the flame to be calculated.

There is a characteristic dimension $\mathrm{k}_{\mathrm{g}} / \mathrm{V}_{\mathrm{a}}$ in the gas phase (air) which exists as a finite distance only so long as there is relative motion between the heat sources and the medium. It is, for example, the scale of the gradient for a plane thermal wave in an infinite medium where the temperature rise ' $\theta^{\prime}$, a distance $x$ ahead of the plane moving at $V_{a}$ and at a temperature $\theta_{0}$ is:

$$
\theta=\theta_{0} \bar{e}^{V_{a} x / K g}
$$

and the heat transfer ahead is:

$$
q^{\prime \prime}=-K_{s}\left(\frac{d \theta}{d_{x}}\right)_{0}=\rho_{f, i q} C_{p} \theta_{0} V_{a}
$$


as required by a simple energy balance. Note that $\rho_{f, i g}$ is not the density of the fuel ahead unless it is uniformly heated, otherwise it is a dependent variable. This equation shows, at its simplest, how the forward conduction is in equilibrium with a convective term.

Estimates of the value of $V_{a}$ induced by a Elame in a quiescent atmosphere $(31)$ give:

$$
V_{a}=\left(\frac{\nu \cdot g \cdot q_{f} Y_{0 x}}{r C_{p} \cdot T_{0}}\right)^{1 / 3}
$$

For typical values of the parameters on the right hand side $V_{a}$ is a $\mathrm{few} \mathrm{mm} / \mathrm{sec}$ wich is of the same order of magnitude as that of the fuel gases emerging from the pyrolysis zone. This disturbance to the opposed flow has, one supposes, an effect but more behind the pyrolysis front. Wichman and Agrawal have discussed this in some detail(32).

Most theory has been based on a steady velocity of spread. In the system shown in Fig 6.

Thick homogenous solid (opposed flow)

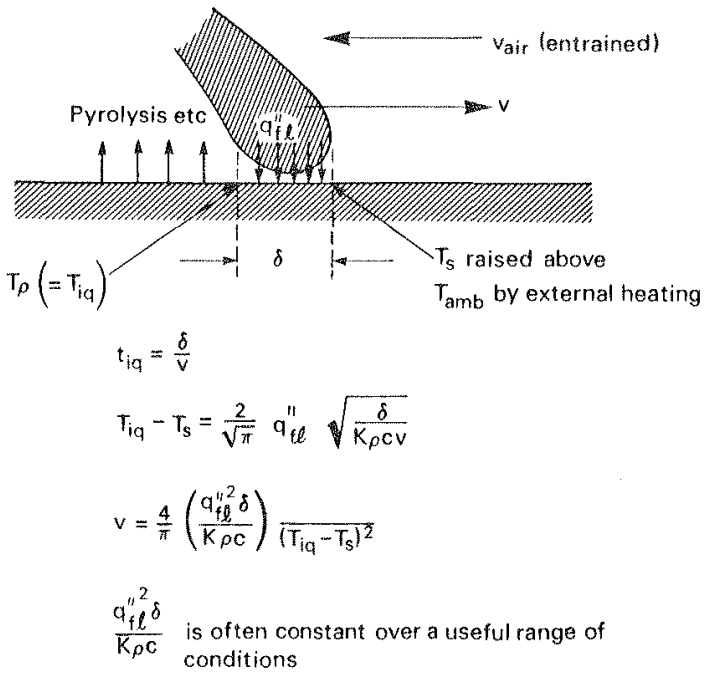

Figure 6 Opposed flow (after Quintiere)

there appears to be no extra forward conduction (other than that in the forward convection) provided there is no energy loss from the system. 
However, if radiation losses are allowed for there can be such conduction so it is possible that radiation loss can be a factor in one type of extinction $(33,34)$.

de Ris incorporated radiation in his models of flame spread and the combination of two strip sources (see Fig 7) gives the temperature rise as:

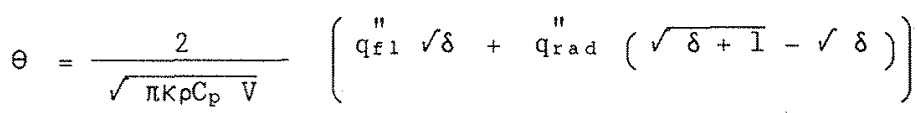

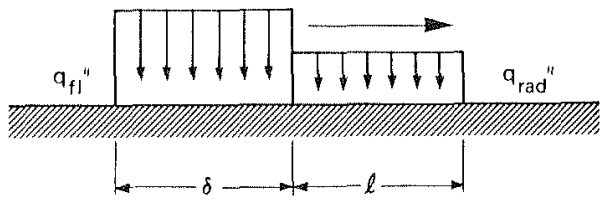

Figure 7 Opposed flow - two strip heating sources

A wide vertical radiator, of height $H$, and normal to the surface has a view factor $\phi$ of $1 / 2$, less if the flame is inclined to the rear as in opposed flow. 1 , is of order $\mathrm{H}$ and:

$$
\mathrm{q}_{\mathrm{rad}}^{\prime \prime} \simeq \varepsilon \sigma\left(\mathrm{T}_{\mathrm{f} 1} 4-\mathrm{T}_{\mathrm{s}}{ }^{4}\right) / 2
$$

where $\varepsilon$ is the flame emissivity and $T_{s}$ is the surface temperature $\ll T_{f}$ The magnitude of:

$$
\theta_{i g} \sqrt{\frac{\pi}{2} K \rho C_{p} V}
$$

requires the major component to be $\mathrm{qfl}^{\prime \prime} \sqrt{\delta}$ because otherwise unrealistically high values of $\varepsilon$ are required. The radiation term may be the dominant one in concurrent spread.

In opposed flow theory a pre-heating distance ' $\delta$ ' or $\left(\mathrm{k}_{g} / \mathrm{V}_{a}\right)$ is assumed, $\mathrm{q}_{\mathrm{f} i}^{\prime 2} \delta$ or $\left(\mathrm{q}_{\mathrm{f}}^{\prime \prime 2} \mathrm{k}_{\mathrm{g}} / \mathrm{V}_{\mathrm{a}}\right)$ can be shown, by experiments, to be effectively constant over a useful range of conditions (viz a range of $T_{s}$ which can be altered by differences in the pre-heating conditions). This is the basis of the engineering use of spread of flame test datal35). The insensitivity of $\mathrm{qfl}^{\prime \prime} \delta$ to the external heating conditions provides a justification for the use of conventional spread of flame tests by 
modellers to provide data which can be applied to circumstances other than those used in standard tests.

Although tests for wall linings based on opposed flow flame spread are over 40 years old and have been standardised as tests in several countries it is only recently that they can be described as scientifically based tests in the sense of their being subject to quantitative modelling (and recognised as such by the relevant Iso committee).

The origin of the British Flame Spread Test - a prototype for several others employing opposed flow flame spread - was a series of experiments on the hazard of spread in a corridor incompletely interpreted as being driven by opposed flow (downward) flame spread. It is fortuitous too that tests of this type should be capable of being modelled long after their adoption on pragmatic grounds. But what other older generation tests have been modelled?

In recent times various national standards organisations including the British Standards Institution $(36)$ have formalised the procedure for developing fire tests by declaring that first the hazard be identified and the test be then developed.

We have discussed flame spread as a flux qfil over a distance $\delta$ (the Quintiere model) and the total heat supply is $q_{f 1} \delta$ which is, approximately:

$$
\alpha K_{g}\left(T_{f 1}-T_{p}\right)
$$

where $\alpha$ is ' $0(1)$. Delichatsios (37) revised de Ris's theoretical evaluation and gives:

$$
\alpha=\frac{\pi}{4}
$$

It is interesting that a semi-infinite uniform plane source (see Fig 8) transfers a total of:

$$
\alpha K_{g}\left(T_{f 1}-T_{p}\right)
$$

to unit area ahead of the inclined plane where $T_{f_{1}}$ is here the temperature of the plane at infinity and, for $\theta=\pi / 2, \quad \alpha=2 / \pi$ but falls to zero as $\theta$ approaches zero.

Since most real building materials are not homogeneous, theory must be expected to provide a validated structure for some materials but can hardly be expected to cope with all materials where there may be problems of melting, intumescence and cracking.

To sum up, there is valuable progress on the scientific aspects of opposed flow flame spread and on its application to fire safety engineering and, with some reservation, to fire testing. Upward concurrent flame spread is another matter. 


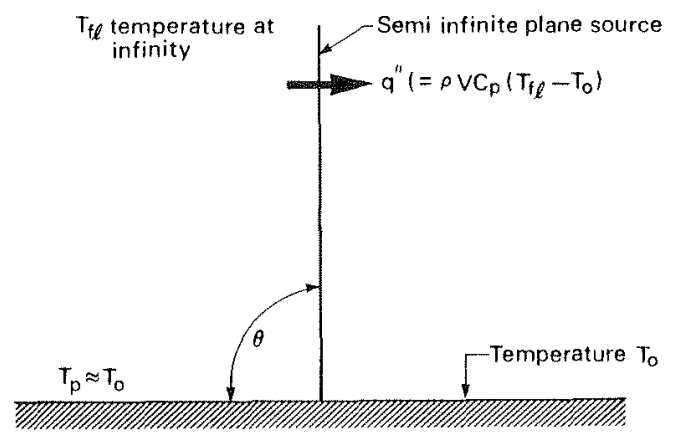

Figure 8 Moving half plane source

\section{Flame Spread up a Wall}

Delichatsios et al(38) have recently been making numerical simulations of flame spread. They explicitly require that the input of material properties should be measurable by flammability apparatus*. This in itself implies that the 'properties' - be they basic or effective engineering properties - should be the 'tools' for describing flame spread processes in detail. This is the important link between research and testing, which will, one expects, eventually drive the regulatory system for controlling the hazard from flammable surfaces.

Saito, Quintiere and Villiams $(39)$ have described a purely thermal model which implies some interesting conclusions.

All models of flame spread up thick solids are so far two-dimensional and the models of Saito et al and of Hasemi ${ }^{(40)}$ are based on quasi-steady flame spread theory. This approximation is clearly less satisfactory near the initiation of the spread than later. However, if ve follow Saito et al we identify the heating distance ${ }^{\prime} \delta^{\prime}=\mathrm{X}_{\mathrm{f} \perp}-\mathrm{X}_{\mathrm{O}}$ over which the net flux $q_{f \prime} I$ is assumed uniform. Longitudinal conduction was neglected and the classic ignition equation (28) is used. We then have:

$$
\theta_{i g}=T_{i g}-T_{s}
$$

where $T_{s}$ is the temperature (assumed uniform) ahead of the flame, the ambient temperature or that dependent on external radiation. The heating time ' $t$ ' was taken as:

$$
\frac{X_{f 1}-X_{p}}{V}=t_{i q}
$$

* state of art equipment, not national standards in general. 
with:

$$
V=\frac{d X_{p}}{d t}=\frac{X_{f 1}-X_{p}}{t_{i g}}
$$

where:

$$
t_{i g}=\frac{\pi}{4} \frac{\kappa_{p C_{p}}}{\left(T_{i g}-T_{5}\right)^{2} q_{f L^{2}}^{\prime \prime}}
$$

Wichman and Agrawal (32) derive this equation and discuss the theories of Saito et al, de Ris, and Quintiere in a more general but 2-dimensional context involving the gas phase and pyrolysis.

Conventionally $\mathrm{X}_{\mathrm{f} 1}$ is taken as proportional to the $2 / 3$ power of the rate of heat release based on a line or horizontal source but Saito, Quintiere and Williams argued that there was some experimental evidence and some physical argument for a higher power when the source was distributed vertically. Therefore they took, for simplicity, a linear relationship:

$$
\mathrm{X}_{\mathrm{F}}=\mathrm{K}\left(\dot{Q}^{\prime}+\mathrm{q}_{\mathrm{m}} \int_{0}^{\mathrm{X}_{\mathrm{p}}} \mathrm{m}^{\prime \prime} \mathrm{dx}\right)
$$

where $Q^{\prime}$ is the convective heat output per unit width of burner and $q_{m}$ is the heat release per unit mass of pyrolized fuel. They constructed a linear integral equation from equations (32) and (34) and discussed the conditions for an asymptotically exponential value of $\mathrm{dx} / \mathrm{dt}$ at long times. They did this for two forms of $m^{\prime \prime}(t)$ viz:

$$
\begin{aligned}
& m^{\prime \prime}(t)=m_{0} "=\text { constant } \quad\left(t_{i g} \ll t_{B}+t_{i g}\right) \\
& \text { and } m^{\prime \prime}(t) \propto 1 / \sqrt{t-t_{i g}}
\end{aligned}
$$

Equations (32) and (34) can be subjected ${ }^{(41)}$ to Laplace transformation to give, respectively:

$$
p \bar{x}_{p}-x_{p o}=\frac{\bar{x}_{f l}-\bar{x}_{p}}{t_{i g}}
$$

where $\mathrm{p}$ is the Laplacian operator and the - over the variable denotes the transformed variable, $x_{p o}$ is the initial value of $x_{p}$ 
and:

$$
\overline{\mathrm{x}}_{\mathrm{f} 1}=\mathrm{K}\left(\overline{\mathrm{Q}}^{\prime}+\mathrm{q}_{\mathrm{m}} \overline{\mathrm{m}}^{\prime \prime} \mathrm{p} \overline{\mathrm{x}}_{\mathrm{p}}\right)
$$

from which:

$$
\bar{x}_{p}=\frac{K \bar{Q} \prime / t_{i q}+x_{p o}}{p+1 / t_{i q}-K q_{m} \bar{m}^{\prime \prime} p / t_{i g}}
$$

We shall also consider the form used by Magnusson \& Sundström ${ }^{(42)}$ :

$$
m^{\prime \prime}=m_{\circ}^{\prime \prime} e^{-\beta\left(t-t_{i g}\right)}
$$

and in addition:

$$
\mathrm{m}^{\prime \prime}=A t e^{-\beta\left(t-t_{i g}\right)}
$$

The inverse square root form has a non-finite maximum value and non-finite integral, making it difficult to compare with the others. We shall identify $\gamma$ as $1 / t_{B}$.

These all produce simple forms for " $x_{f} 1$ can be evaluated in terms of exponentials. The procedure necessarily gives the same results as does the analysis by Saito, Quintiere and Williams for $t \rightarrow \infty$ and the denominator in equation (39) produces a quadratic in ' $p$, and the roots may be both positive, conjugate or both negative. These three types of solutions correspond respectively to an initial propagation which dies out asymptotically in time, at a finite time (the value of $x_{p}$ unrealistically decreasing after a certain time) or one which accelerates.

Each of the three finite forms of $m$ " defines a requirement for a propagating fire. For the exponential and the step function:

$$
\mathrm{Kq}_{\mathrm{m}} \ddot{m}_{\circ} \text {. Funct }\left(\mathrm{t}_{\mathrm{ig}} / \mathrm{t}_{\mathrm{B}}\right)>\text { constant }
$$

For the third form one has:

$$
\mathrm{Kq}_{m} \mathrm{At}_{i g} \text {. Funct }\left(\mathrm{t}_{i_{g}} / \mathrm{t}_{B}\right)>\text { constant }
$$

The differences are partly due to the differences in defining $t_{B}$ and mo (and A) and partly due to the real differences in the shapes of the $m$ " ( $t$ ) curves. 
For the exponential form the condition is exactly:

$$
\mathrm{Kq}_{m} \mathrm{~m}_{\circ}^{\prime \prime}>\left(1+\sqrt{\frac{\mathrm{t}_{\mathrm{ig}}}{\mathrm{t}_{\mathrm{B}}}}\right)^{2}
$$

To get some idea of a comparison we define characteristics:

$$
m_{c h}^{\prime \prime} t^{1 / 2}=\frac{1}{2} \int_{0}^{\infty} m^{\prime \prime} d t=\int_{0}^{t 1 / 2} m " d t
$$

so normalising the time scale to the time required to produce half the total mass. Clearly other fractions could be chosen (and perhaps derived by minimising differences between selected shapes) but the important matter is to recognise that fuel released early plays a greater role in fire growth than that released later.

Using this procedure the three forms of $\mathrm{m}^{\prime \prime}(\mathrm{t})$ give similar requirements for an indefinite propagating flame (see Fig 9).

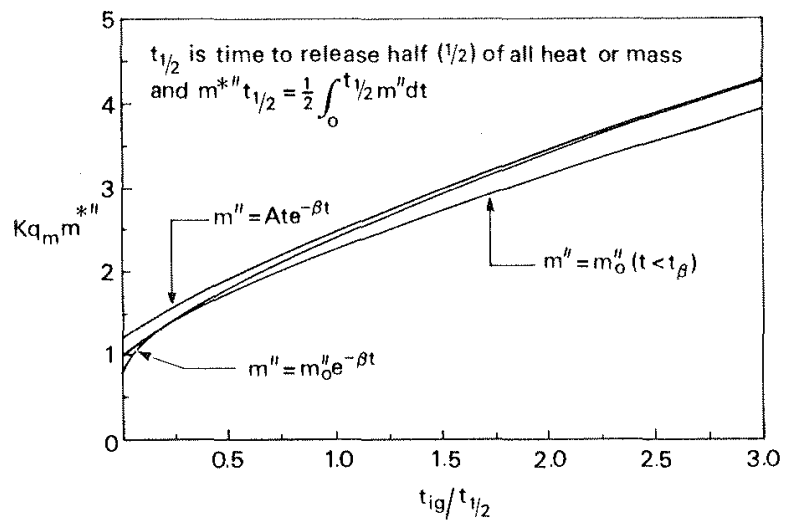

Figure 9 Conditions for propagation

$q_{m} m_{c h}$ can be defined as $Q_{c h}^{\prime \prime}$ a characteristic rate of heat release. At this point the engineer may be tempted to abandon theory (which suffers from the defect of being two-dimensional which is inadequate for fires just starting) and recognise that we have a dimensionless criterion 
between $\mathrm{KQ}_{\mathrm{ch}}^{\prime \prime}$ and $\mathrm{t}_{\mathrm{ig}} / \mathrm{t}_{1 / 2}$ which is amenable to experimentation exploiting conventional material properties, perhaps with the inclusion of qui $\delta$. Even the assumption of linearisation of flame length is not crucial for interpreting experiments because the term $\mathrm{KQ}_{\mathrm{ch}}^{\prime \prime}$ is no more than a characteristic ratio of flame length to pyrolysis length $x_{0} / x_{p o}$. Perhaps the shape of the $m^{\prime \prime}(t)$ charactistic may not be so important as might at Eirst be thought.

So far all that has been examined is the condition for indefinite spread (given a flame flux and an external pre-heating condition).

Conditions governing limited spread will involve the conditions of ignition, the support given by the burner and the abandonment of the steady state approximation.

In practical design these are rather more important than the condition of a propagating fire which has got away. Some aspects of the discussion of upward flame spread are relevant to spread under inclined surfaces or over them if the flames are bent over as was the case in the Kings Cross Underground fire. One would expect the analysis of spread rates of both kinds to involve the correlation of flame length to pyrolysis length.

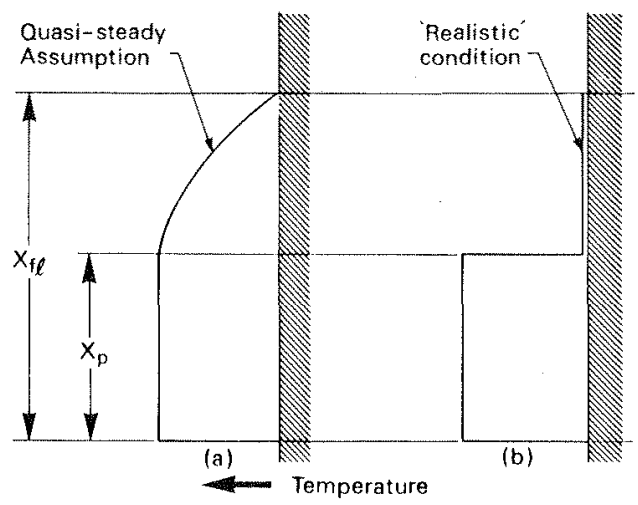

Figure 10 Initial temperatures on solid surface

The initial condition shown in Fig 10a ie a finite temperature rise $x_{p}<x<x_{f}$ at $t=0$ corresponds to the quasi-steady state.

Clearly for the initial condition shown in Fig $10 \mathrm{~b}$ which is different theoretically but not necessarily more practical, the more detailed analyses of the type discussed by Delichatsios et al and Wichman and Agrawal are required.

If the initial temperature was distributed as a step function there could be no propagation if $t_{B}\left\langle t_{i g} \text { and if } t_{i g}\right\rangle_{B}$ the initial spread could be discontinuous. Emmons has discussed a different but analagous problem $(43)$. 


\section{FIRE TESTING}

Such procedures - combining theory and experiment - are steps on the road charted by Howard Emmons as the way to develop a rational, scientifically based approach to the control and investigation of fire hazards.

No such commitment appears to have been made until recently in Europe except in the Nordic countries, partly perhaps because the average numerically based fire safety record in Europe is perceived to be better than the North American, partly because many of those influential in controlling and devising regulations, be they administrators or fire service officers, are unfamiliar with the engineer's approach to problems, preferring the past prescriptive rules. However there has been an acceptance in principle in the UK of control by design (44). The increased demand in the UK by the fire service for higher educational standards is a new factor so one hopes these attitudes will change even faster.

The influence forcing these changes are partly political (deregulation), partly the growth of the subject and partly one hopes, the need for objectivity in European harmonisation. Unfortunately initiatives in $1979(45)$ by the Commission of the European Communities (CEC) for research on fire growth (to provide a basis for harmonisation of reaction to fire' tests) were not supported and now there is a tendency for apparently well thought out solutions to be regarded as long term for the future, so as to justify retaining old solutions as interim solutions. However opposing tendencies have appeared and I hope they will prevail.

\section{CONCLUSION}

I have discussed a few topics of technical interest to the fire scientist and to the growing profession of fire safety engineers. The Association will endeavour to serve their interests by raising the status of the subject by maintaining, by improving its scientific quality and by responding to their needs.

\section{NOTATION}

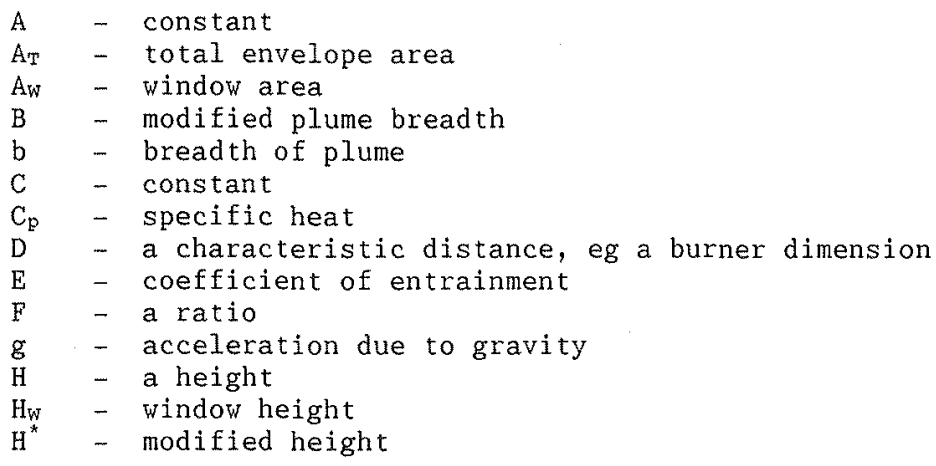




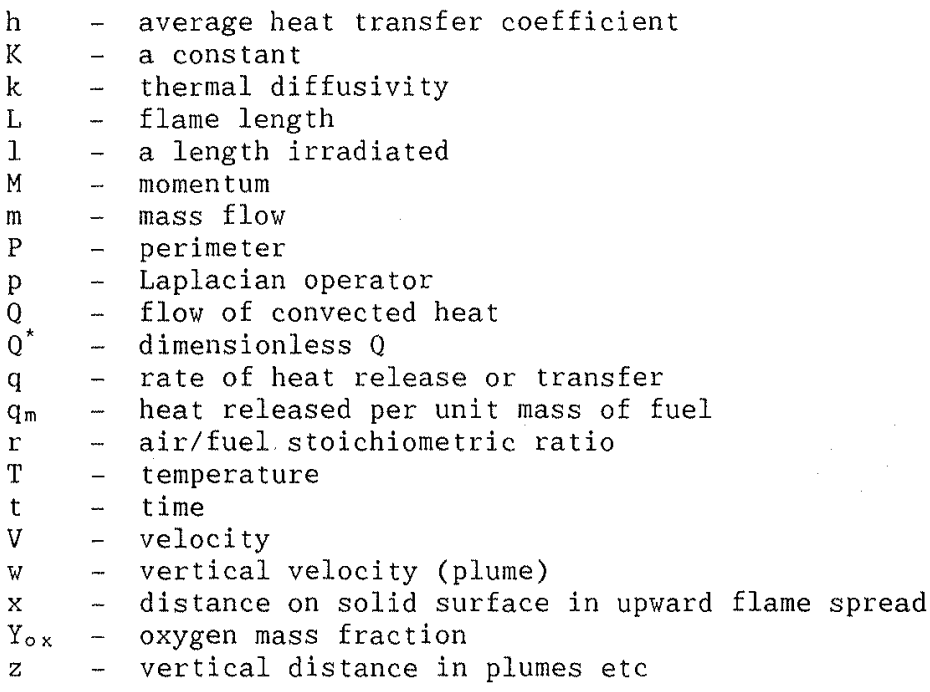

\section{GREEK SYMBOLS}

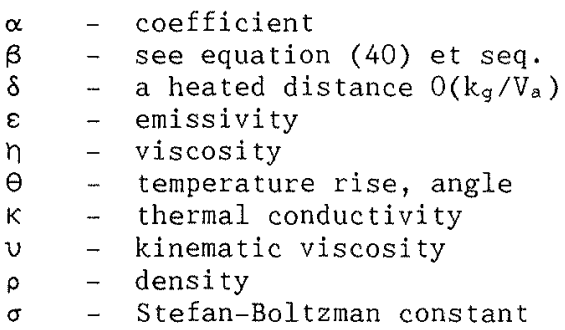

\section{SUFFICES, SUBSCRIPTS}

- air

- burn

- centre line

- characteristic value

- fire

- fuel

- flame

- gas phase

- ignition

- ambient, initial

- pyrolyis

- surface

- total

- half of total

- window, opening

- per unit area

- per unit width or length 


\section{REFERENCES}

1. Heskested, G. 'Fire Plumes'. Handbook of Society of Fire Protection Engineers. SFPE Boston 1988, Chapter 1-6, p 107.

2. McCaffrey, B. 'Plame Height' idem Chapter 1-18, p 298.

3. Evans, D. 'Ceiling Jet Flows' idem Chapter 1-9, p 138.

4. Morton, B.R., Taylor, G.I. and Turner, J.S. Proc. Roy. Soc. A234, 1 (1956).

5. Taylor, G.I. The Dispersal of Fog from Airfield Runways, ed Walker, E.G. and Rox, D.A. Min of Supply 1946, p 230 and 'Fire under Influence of Natural Convection', Int Symposium on the use of Models in Fire Research. National Academy of Sciences - National Research Council, Washington DC, publication 786 , (1961).

6. Schmidt, W. Zeit für Ang Mathematik under Mechanik (1941), 21, 265-278 and $351-363$.

7. Rouse, Hunter, Yih, C.S. and Humphreys, H.W. Tellus (1952), 4, pp 201-210.

8. Cetegen, B.M., Zukoski, E.E. and Kubota, T. Combustion Science and Technology (1984), 39, pp. 305-331.

9. Thomas, P.H. Ninth Symposium (International) on Combustion. The Combustion Institute, Pitsburgh (1963), p 844.

10. Hinkley, P. Fire Safety Journal, 10 (1), 1986, p 57.

11. Lee, S-L., and Emmons, H.W. J Fluid Mech, 11, 1961 p 353.

12. Morton, B.L. Tenth Symposium (International) on Combustion. The Combustion Institute, Pittsburgh (1965), p 973.

13. Ricou, F.P. and Spalding, D.B. J Fluid Mech, 11, 1961, p 21.

14. McCaffrey, B.J. NBSIR 79-1910 National Bureau of Standards, Washington US, October 1979.

15. Yokoi, S. 'Study on the Prevention of Fire Spread caused by Upward Current'. Japanese Min of Construction. Building Res Inst. Report No 34, Tokyo, 1960.

16. Morgan, H.P and Marshall, N.R. 'Smoke Hazards in covered multi-level Shopping Malls. Some studies using a 2-storey Mall'. Current Paper 48/75. BRE, Borehamwood 1975.

17. Thomas, P.H. and Karlsson, B. On the Length of Flames under Ceilings'. SE-LUTVDG/TVBB-3059. Dept of Fire Safety Engineering, Lund University, December 1990.

18. Heskested, G. Fire Safety Journal (1983), 5, 109. 
19. Babrauskas, V. Fire and Materials, 4(3), 1980, p 119.

20. You, H. and Faeth, G.M. 'An Investigation of Fire Impingement on a Horizontal Ceiling'. Mech Eng Dept, Pennsylvania State University; 1981 .

21. Gross, D. 'Measurements of Flame Lengths under Ceilings'. NIST IR88-3835. National Institute of Standards and Technology, Washington DC, 1988.

22. Andersson, $C$. and Giacome11i, G. 'Ett Modelrum : Lågor', Dept of Fire Safety Engineering, Lund University, 1985.

23. Heskested, G. and Delichatsios, M.A. 17th Symposium (International) on Combustion. Combustion Institute, Pittsburgh (1979), p 1113.

24. Willianson, R.B., Mowrer, F.W. and Fisher, F.L. Combustion Science and Technology (1984), 41, pp 83-99.

25. Tewarson, A. Combustion and Flame (1972), 19, 363-371.

26. Friedman, R. 'The Behaviour of Fires in Compartments'. International Symposium on Fire Safety of Combustible Materials, Edinburgh University (1975), pp 100-113.

27. Babrauskas, V. and Wickstrom, U. Combustion and Flame 34, 195, 1979.

28. Bøhm, B. and Hadvig, S. Combustion and Flame, 1982, 44 (1-3), 201-221.

29. Bullen, M.L. and Thomas, P.H. (1979). 17th Symposium (International) on Combustion. The Combustion Institute, Pittsburgh, p 1139-1146.

30. de Ris, J.N. (1969). 12th Symposium (International) on Combustion. The Combustion Institute, Pittsburgh, p 241-252.

31. Altenkirch, R.A., Eichorn, R. and Shang, P.C. Combustion and Flame $(1980), 37$ p $71-83$.

32. Wichman, I.S. and Agrawal, S. Combustion and Flame 1991, 83, p $127-145$.

33. Subulkin, M., Kim, J. and Creeden, J.V. Combustion Sci \& Technology, 14, 43, 1976 .

34. Subulkin, M., Kulkarni, A.K. and Annamalai, K. 18 th Symposium (International) on Combustion. The Combustion Institute (1981), p 611 .

35. Quintiere, J.G. Fire and Materials (1981), 5, p 52-60.

36. British Standard Guide to Development and Presentation of Fire Tests and their use in Hazard Assessment. British Standards Institution BS $6336: 1982$. 
37. Delichatsios, M.A. Conbustion Sci and Technology 1986, 44 (5-6) p 257-267.

38. Delichatsios, M. M., Mathews, M.K. and Delichatsios, M.A. Upward Flame Spread Simulation Code: Version 1: Non-charring fuels. Factory Mutual Research, November 1990.

39. Saito, K., Quintiere, J.G. and Williams, F.A. Upward Turbulent Flame Spread. International Symposium on Fire Safety Science, Gaithersburg. Hemisphere Publishing Corporation, NY, 1985, p 75.

40. Hasemi, Y., Yoshida, M. and Nohara, A. Building Research Institute, Tsukento, Japan 1990.

41. Thomas, P.H. and Karlsson, B. On Upward Flame Spread. SELUTVDG/TVBB 3058. Dept of Fire Safety Engineering, Lund University, December 1990.

42. Karlsson, B., Magnusson, S.E. and Andersson, B. Numerical Simulation of Room Fire Growth on Combustible linings and a Rational Classification Model. Interflam 190, p 43-54, London Interscience Communications Ltd 1990.

43. Emmons, H.W. Fire in the Forest. Fire Res Abs \& Reviews. Nat Acad Sci - Nat Res Council, Washington DC (1963), 5(3), p 163.

44. Building Regulations (England and Wales) HMSO, London 1985.

45. Commission of the European Communities (1979). Protection of Buildings against fire. Draft Research Programme DGIII $827 / 79$. 